\title{
Rate of candidiasis among HIV-infected children in Spain in the era of highly active antiretroviral therapy (1997-2008)
}

Alejandro Álvaro-Meca', Julia Jensen ${ }^{2}$, Dariela Micheloud ${ }^{3,4}$, Asunción Díaz ${ }^{5}$, Dolores Gurbindo ${ }^{6}$ and Salvador Resino ${ }^{4^{*}}$

\begin{abstract}
Background: Candidiasis is the most common opportunistic infection seen in human immunodeficiency virus (HIV)-infected individuals. The aim of our study was to estimate the candidiasis rate and evaluate its trend in HIVinfected children in Spain during the era of highly active antiretroviral therapy (HAART) compared to HIV-uninfected children.

Methods: We carried out a retrospective study. Data were obtained from the records of the Minimum Basic Data Set from hospitals in Spain. All HIV-infected children were under 17 years of age, and a group of HIV-uninfected children with hospital admissions matching the study group by gender and age were randomly selected. The follow-up period (1997-2008) was divided into three calendar periods: a) From 1997 to 1999 for early-period HAART; b) from 2000 to 2002 for mid-period HAART; and c) from 2003 to 2008 for late-period HAART.
\end{abstract}

Results: Among children with hospital admissions, HIV-infected children had much higher values than HIVuninfected children during each of the three calendar periods for overall candidiasis rates (150.0 versus 6.1 events per 1,000 child hospital admissions/year $(p<0.001), 90.3$ versus $3.1(p<0.001)$, and 79.3 versus $10.7(p<0.001)$, respectively) and for non-invasive Candida mycosis (ICM) rates (118.5 versus $3.8(p<0.001), 85.3$ versus 2.3 $(p<0.001)$, and 80.6 versus 6.0 ( $p<0.001)$, respectively). In addition, HIV-infected children also had higher values of ICM rates than HIV-uninfected children, except during the last calendar period when no significant difference was found (32.4 versus $1.2(p<0.001)$, 11.6 versus $0.4(p<0.001)$, and 4.6 versus $2.3(p=0.387)$, respectively). For all children living with HIV/AIDS, the overall candidiasis rate (events per 1,000 HIV-infected children/year) decreased from 1997-1999 to 2000-2002 (18.8 to 10.6; $p<0.001$ ) and from 2000-2002 to 2003-2008 (10.6 to 5.7; $p=0.060$ ). Within each category of candidiasis, both non-ICM and ICM rates experienced significant decreases from 1997-1999 to 2003-2008 (15.9 to 5.7 ( $p<0.001)$ and 4.1 to 0.3 ( $p<0.001$ ), respectively).

Conclusions: Although the candidiasis rate still remains higher than in the general population (from 1997 to 2008), candidiasis diagnoses have decreased among HIV-infected children throughout the HAART era, and it has ceased to be a major health problem among children with HIV infection.

Keywords: AIDS, Candidiasis, HAART, Infection, Pediatric, Epidemiology

\footnotetext{
* Correspondence: sresino@isciii.es

${ }^{4}$ Centro Nacional de Microbiología, Instituto de Salud Carlos III, Carretera Majadahonda- Pozuelo, Km 2.2, Madrid, Majadahonda 28220, Spain Full list of author information is available at the end of the article
} 


\section{Background}

In developed countries, the number of human immunodeficiency virus (HIV)-infected children receiving highly active antiretroviral therapy (HAART) has increased since 1996. During its earliest years, HAART had important limitations such as only a few approved pediatric formulations of protease inhibitor (PI), difficulties with administration and low adherence, as well as issues with unsuitable formulations and inadequate pharmacokinetics [1-3]. The introduction of new drugs and formulations after $1999[4,5]$ extended the use of HAART to a larger number of children [6]. And after 2002, new HAART regimens allowed for increased adherence and effectiveness [7].

In the pre-HAART era, opportunistic infections were the primary cause of death in HIV-infected children $[8,9]$. Current HAART regimens work by achieving maximal viral load suppression and increasing CD4+ Tcell (CD4+) counts [10], and have resulted in a substantial and dramatic decrease in acquired immunodeficiency syndrome (AIDS)-related opportunistic infections, morbidity, hospitalizations and deaths in HIV-infected children [8,11-15].

Candidiasis is the most common opportunistic infection seen in HIV-infected children, particularly in HIVinfected children with persistently low CD4+ counts [16]. Localized disease caused by Candida is characterized by limited tissue invasion in the skin or mucosa. Once the organism penetrates the mucosal surface and widespread hematogenous dissemination occurs, invasive Candida mycosis (ICM) ensues [17]. ICM usually occurs in critical situations with advanced stages of immune-suppression [16], and it has proved to be a significant cause of morbidity in HIV-infected patients during the course of hospitalization [17]. However, the impact of HAART has resulted in a decline in the incidence of candidiasis in this population $[11,14,18]$. Candida-specific immunity is one of the earliest to recover in response to HAART, which is consistent with increases in CD4+ counts and the disappearance of clinical signs in response to HAART $[19,20]$.

The aim of our study was to estimate the candidiasis rate and evaluate its trend in HIV-infected children in Spain during the HAART era compared to HIVuninfected children.

\section{Methods}

\section{Study population}

We carried out a retrospective study from 1997 to 2008 among all HIV-infected children under 17 years of age with a hospital admission in Spain (Figure 1) [21]. In addition, we selected a control group composed of 4 HIV-uninfected children for each HIV-infected child studied. This control group (selective 'cohort' which has not been exposed to HIV or HAART) was randomly selected from all HIV-uninfected children under 17 with hospital admissions and matched by gender and age.

Data were obtained from the records of the Minimum Basic Data Set (MBDS) of hospitals in Spain, as we previously described [21]. The MBDS is a database that captures $97.7 \%$ of all public hospital admissions and $25 \%$ of all private hospital admissions in Spain. We did not have data permitting us to estimate the proportion of HIV-infected children in Spain who received care at a private hospital. However, all HIV-infected children are treated through the public health system in Spain and, thus, would be likely to receive their care at public hospitals. The MBDS system showed no significant variations during the whole study period (1997-2008).

Data were treated with full confidentiality, according to Spanish legislation. Patient identifiers were deleted before the database was provided to the authors in order to keep strict patient confidentiality. It is not possible to identify patients at individual levels either in this paper or in the database. Given the anonymous and mandatory nature of the data, informed consent was neither required nor necessary. The Spanish Ministry of Health evaluated the protocol of our investigation and considered that it met all ethical aspects according to Spanish legislation so provided us with the database. The study was approved by the Research Ethic Committee of the Instituto de Salud Carlos III (ISCIII).

The MBDS provides the encrypted patient identification number, sex, date of birth, dates of hospital admission and discharge, medical institutions providing the services, the International Classification of Diseases, 9th ed, Clinical Modification (ICD-9-MC) codes of diagnoses and procedures, and outcome at discharge. In this study, HIV infection was assigned to patients who had an ICD-9-CM code of 042 (HIV disease) or V08 (Asymptomatic HIV infection status).

\section{Exposure variables}

We analyzed two kinds of exposure variables:

i.) HIV infection: we analyzed two study groups according to HIV status: HIV-uninfected children and HIV-infected children.

ii.) HAART, the standard treatment for HIV-infected children: in this study, we divided the follow-up period from 1997 to 2008 into three subperiods or calendar periods, according to the widespread use of HAART in children [21]: a) from 1997 to 1999 (1997-1999) for early-period HAART, b) from 2000 to 2002 (2000-2002) for mid-period HAART, and c) from 2003 to 2008 (2003-2008) for lateperiod HAART. 


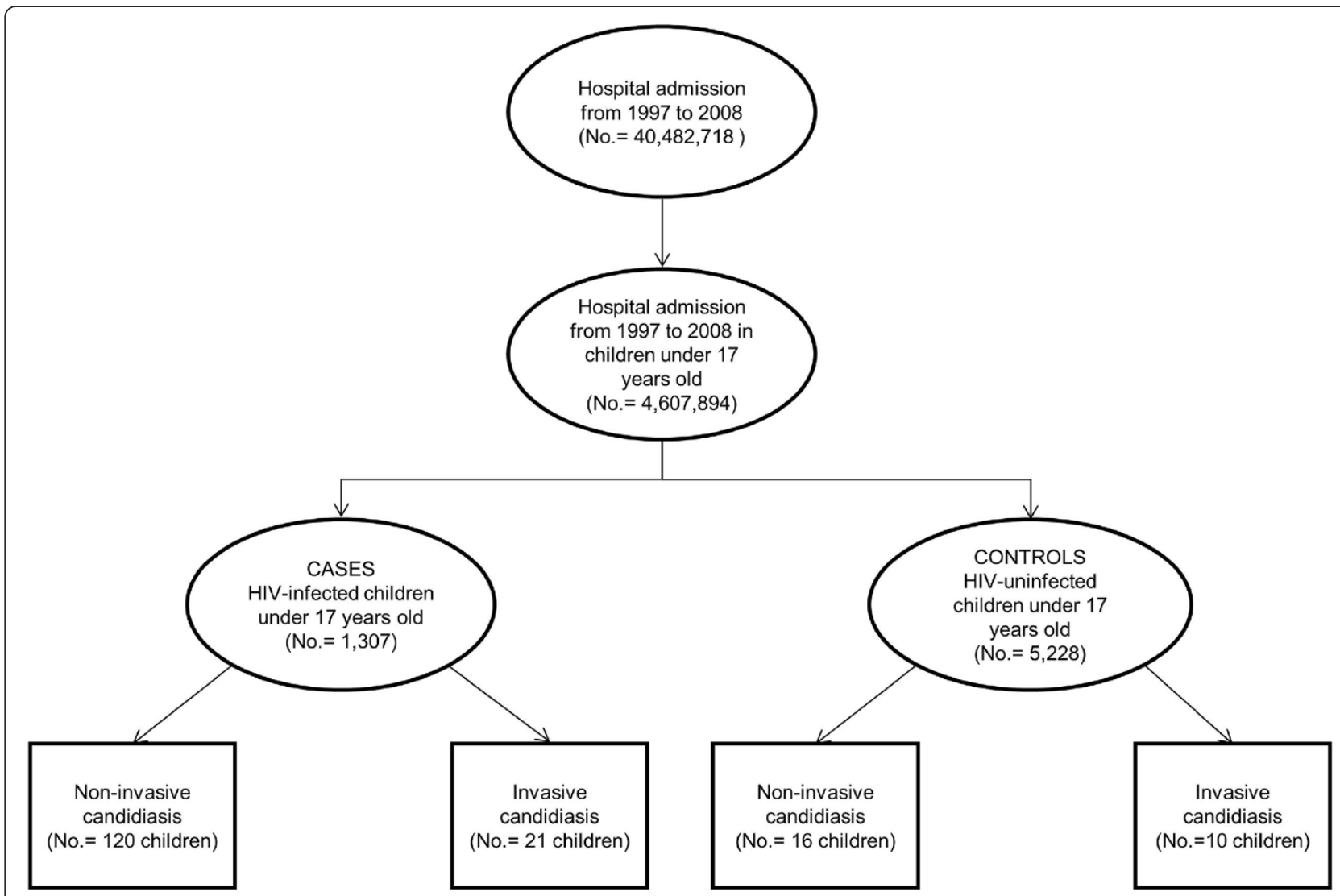

Figure 1 Flow-chart for the selection of HIV-infected children (cases) and HIV-uninfected children (controls) under 17 years old and candidiasis diagnosis in Spain from 1997 to 2008.

\section{Outcome variables}

The index episode was defined as the occurrence of a hospital discharge with candidiasis diagnosis via ICD-9 codes:

i.) Non-ICM: candidiasis of mouth (112.0), candidiasis of vulva and vagina (112.1), candidiasis of other urogenital sites (112.2), candidiasis of skin and nails (112.3), candidal otitis external (112.82), candidal esophagitis (112.84).

ii.) ICM: candidiasis of lung (112.4), disseminated candidiasis (112.5), candidal endocarditis (112.81), candidal meningitis (112.83), candidal enteritis (112.85), other candidiasis of other specified sites (112.89), candidiasis of unspecified site (112.9), neonatal Candida infection (771.7).

Hospitalization was defined as a discharge record in the MBDS, and children who were readmitted with candidiasis in the same hospital and in the same calendar year were counted as new diagnoses of candidiasis.
Estimation of the number of children living with HIV/AIDS in Spain from 1997 to 2008

The estimation of the number of children living with HIV/AIDS in Spain was made from two official registries of HIV-infected children (see Additional file 1), as previously described [21]:

i. The number of HIV-infected children in the Madrid cohort, which was supplied by the Madrid Cohort of HIV Children (The Madrid HIV Paediatric Infection Collaborative Study Group).

ii. The number of HIV-infected children with a diagnosis of AIDS in Spain (AIDS-S), which was supplied by the Spanish National AIDS Register (National Centre for Epidemiology, Instituto de Salud Carlos III,).

\section{Statistical analysis}

We calculated the rate or the number of events per 1,000 children-year, for overall and specific candidiasis diagnosis, according to each calendar period. The numerator was 
the number of children and the number of candidiasis diagnoses among HIV-infected children within each period (whole follow-up or calendar period). The denominator was different according to the type of rate calculated: a) for the events per 1,000 children with hospital admission-year, we used number of HIV-uninfected children or HIV-infected children with a hospital discharge within the follow-up period (CMBD data); b) For the events per 1,000 HIV-infected children-year, we used the number of children living with HIV/AIDS in Spain from 1997 to 2008 (see Additional file 1).

Candidiasis rates were compared using Poisson regression. Statistical analysis was performed using the $\mathrm{R}$ version 2.15.0 statistical package (GNU General Public License; http://www.r-project.org/). All tests were two-tailed with $\mathrm{p}$-values $<0.05$ considered significant.

\section{Results}

\section{Study population}

Figure 1 shows the number of HIV-infected children and HIV-uninfected children included in this study. We included 1307 HIV-infected children with at least one hospitalization episode. Of all these, 141 children had 149 candidiasis diagnoses, including 120 children with 128 non-ICM diagnoses and 21 children with ICM diagnoses. In addition, we included a control group of 5228 randomly selected HIV-uninfected children with hospital admissions matched by gender and age. Within the control group, 26 children had candidiasis diagnoses, including 16 children with non-ICM diagnoses and 10 children with ICM diagnoses.

Table 1 shows the epidemiological and clinical characteristics of children with candidiasis diagnoses among the cases (HIV-infected children) and controls (HIV-uninfected children) included in this study. When we analyzed within cases and controls, HIV-uninfected children with ICM diagnoses were older $(\mathrm{p}=0.008)$, while HIV-infected children with ICM diagnoses had longer hospital stays $(p=0.049)$ than children with non-ICM diagnoses. Next, we performed the analysis among diagnostics groups (All candidiasis, non-ICM, and ICM). Overall, the percentage of males was similar among groups, but HIV-infected children were older $(\mathrm{p}=0.016)$ and had longer hospital stays $(\mathrm{p}=0.006)$ than HIV-uninfected children. These trends were maintained within non-ICM group. However, HIVinfected children with ICM diagnosis had higher values of percentage of males $(\mathrm{p}=0.041)$ and length of stay $(\mathrm{p}<$ $0.001)$, but they had the lowest values of age $(\mathrm{p}<0.001)$.

\section{Candidiasis rates among children with hospital admissions}

Among children with hospital admissions, HIV-infected children had a higher overall rate of candidiasis (events per 1,000 children with hospital admission/year) than HIV-uninfected children (107.0 versus 4.9; $\mathrm{p}<0.001)$ (Table 2). By type of candidiasis diagnosis, HIV-infected children had higher rates of both non-ICM and ICM diagnoses than HIV-uninfected children (91.8 versus 3.1 $(\mathrm{p}<0.001)$ and 16.1 versus $1.9(\mathrm{p}<0.001)$, respectively) (Table 2). HIV-infected children also had higher rates of non-ICM than ICM diagnoses $(\mathrm{p}<0.001)$ (Table 2). The most frequent diagnosis in both groups of children (HIV-uninfected and HIV-infected children) was candidiasis of mouth.

When we divide the follow-up period into three separate calendar periods, we find that HIV-infected children had much higher values than HIV-uninfected children for overall candidiasis rates during each of the three periods $(150.0$ versus $6.1(\mathrm{p}<0.001), 90.3$ versus $3.1(\mathrm{p}<$ $0.001)$, and 79.3 versus $10.7(\mathrm{p}<0.001)$, respectively) as well as for non-ICM rates $(118.5$ versus $3.8(\mathrm{p}<0.001)$, 85.3 versus $2.3(\mathrm{p}<0.001)$, and 80.6 versus $6.0(\mathrm{p}<$ 0.001 ), respectively) (Table 3 ). HIV-infected children had higher values of ICM rates than HIV-uninfected children, however during the last calendar period no significant difference was found (32.4 versus $1.2(\mathrm{p}<0.001)$, 11.6 versus $0.4(\mathrm{p}<0.001)$, and $(4.6$ versus $2.3(\mathrm{p}=$ 0.387 ), respectively) (Table 3 ). Of particular importance, the rates of overall candidiasis, non-ICM, and ICM all decreased from 1997-1999 to 2003-2008, however the

Table 1 Epidemiological and clinical characteristics of HIV-infected and HIV-uninfected children with candidiasis diagnoses from 1997 to 2008

\begin{tabular}{|c|c|c|c|c|c|c|c|c|c|c|c|}
\hline & \multicolumn{4}{|c|}{ HIV-uninfected children } & \multicolumn{4}{|c|}{ HIV-infected children } & \multirow[b]{2}{*}{$\begin{array}{l}{ }^{(b)} p- \\
\text { value }\end{array}$} & \multirow[b]{2}{*}{$\begin{array}{l}\text { (c) } p- \\
\text { value }\end{array}$} & \multirow[b]{2}{*}{$\begin{array}{l}{ }^{(d)} p- \\
\text { value }\end{array}$} \\
\hline & $\begin{array}{c}\text { All } \\
\text { candidiasis }\end{array}$ & Non-ICM & ICM & $\begin{array}{l}{ }^{\text {(a) }} p \text { - } \\
\text { value }\end{array}$ & $\begin{array}{c}\text { All } \\
\text { candidiasis }\end{array}$ & Non-ICM & ICM & $\begin{array}{l}{ }^{(a)} p- \\
\text { value }\end{array}$ & & & \\
\hline $\mathbf{N}$ & 26 & 16 & 10 & & 141 & 120 & 21 & & & & \\
\hline Males \# & $10(38.5)$ & $8(50.0)$ & $2(20.0)$ & 0.264 & $70(49.6)$ & $56(46.7)$ & $14(66.7)$ & 0.145 & 0.403 & 1 & 0.041 \\
\hline Age (years) * & $0.5(0 ; 8.7)$ & $0(0 ; 3.2)$ & $9(1.5 ; 11.0)$ & 0.008 & $7(1 ; 11)$ & $7(1 ; 11)$ & $4(2 ; 11)$ & 0.921 & 0.016 & $<0.001$ & $<0.001$ \\
\hline $\begin{array}{l}\text { Length of stay } \\
\text { (days) }\end{array}$ & $6.5(3.2 ; 10.5)$ & $5.5(3.0 ; 7.5)$ & $8.5(7.0 ; 22.0)$ & 0.125 & $13(7 ; 22)$ & $12(7 ; 22)$ & $18(9 ; 42)$ & 0.049 & 0.006 & $<0.001$ & $<0.001$ \\
\hline
\end{tabular}

Values expressed as: (") Absolute number (percentage); ( ${ }^{*}$ ) Median (percentile 25; percentile 75).

Abbreviations: ICM, invasive candidiasis mycosis; HIV, Human immunodeficiency virus.

Significance level (p-values): (a), Non-ICM vs. ICM within a group; (b), all candidiasis between groups, (c); Non-ICM between groups, (d), ICM between groups. Statistically significant differences are shown in bold. 
Table 2 Summary of the number and rates of children with candidias per 1,000 children with hospital admission/year (bold font) and specific candidiasis diagnoses per 1,000 children with hospital admission/year (non-bold font) in HIVinfected children and HIV-uninfected children in Spain from 1997 to 2008

\begin{tabular}{|c|c|c|c|c|c|}
\hline \multirow[b]{2}{*}{ Description } & \multirow[b]{2}{*}{ ICD-9 codex } & \multicolumn{2}{|c|}{ HIV-uninfected children } & \multicolumn{2}{|c|}{ HIV-infected children } \\
\hline & & No. & Rate $(95 \% \mathrm{Cl})$ & No. & Rate $(95 \% \mathrm{Cl})$ \\
\hline All candidiasis & 112.XX & 26 & $5.0(3.1 ; 6.9)$ & 141 & $107.0(90.1 ; 125.7)^{(*)}$ \\
\hline Non-invasive Candida mycosis (Non-ICM) & & 16 & $3.1(1.6 ; 4.6)$ & 120 & $91.8(75.4 ; 108.3)^{(*,+)}$ \\
\hline Candidiasis of mouth & 112.0 & 13 & $2.5(1.1 ; 3.8)$ & 104 & $79.6(64.6 ; 94.7)^{(*)}$ \\
\hline Candidiasis of vulva and vagina & 112.1 & 0 & - & 2 & $1.5(0 ; 3.6)$ \\
\hline Candidiasis of other urogenital sites & 112.2 & 0 & - & 4 & $3.1(0.1 ; 6.1)$ \\
\hline Candidiasis of skin and nails & 112.3 & 3 & $0.6(0 ; 1.2)$ & 5 & $3.8(0.5 ; 7.2)^{(*)}$ \\
\hline Candidal otitis external & 112.82 & 0 & - & 1 & $0.7(0 ; 2.3)$ \\
\hline Candidal esophagitis & 112.84 & 0 & - & 12 & $9.2(4.0 ; 14.4)$ \\
\hline Invasive Candida mycosis (ICM) & & 10 & $1.9(0.7,3.1)$ & 21 & $16.1(9.2 ; 23.0)^{(*)}$ \\
\hline Disseminated candidiasis & 112.5 & 1 & $0.2(0 ; 0.6)$ & 3 & $2.3(0 ; 4.9)^{(*)}$ \\
\hline Candidal enteritis & 112.85 & 0 & - & 5 & $3.8(0.5 ; 7.2)$ \\
\hline Other candidiasis of other specified sites & 112.89 & 6 & $1.1(0.2 ; 2.1)$ & 7 & $5.3(1.4 ; 9.3)^{(*)}$ \\
\hline Candidiasis of unspecified site & 112.9 & 1 & $0.2(0 ; 0.6)$ & 4 & $3.1(0.1 ; 6.1)^{(*)}$ \\
\hline Neonatal candida infection & 771.7 & 2 & $0.4(0 ; 0.9)$ & 2 & $1.5(0 ; 3.6)$ \\
\hline
\end{tabular}

Abbreviations: ICM, invasive candidiasis mycosis; HIV, Human immunodeficiency virus; ICD-9, data are coded according to the International Classification of Diseases (9th revision, Clinical Modification [ICD-9-MC]); Rate, events per 1,000 children with hospital admission/year; $95 \%$ Cl, $95 \%$ of confidence interval. $(\dagger)$ : Significant differences between groups of study within a candidiasis diagnosis category $(p<0.001)$.

$\left(^{*}\right)$ : Significant differences between Non-ICM and ICM categories within a study group $(p<0.001)$.

differences were only significant for HIV-infected children with ICM diagnoses $(\mathrm{p}=0.032)$.

Candidiasis rates among all children living with HIV/AIDS During the follow-up period taken as a whole, the overall rate of candidiasis in all HIV-infected children in Spain (events per 1,000 HIV-infected children/year) was 11.3 ( $95 \%$ of confidence interval $(95 \% \mathrm{CI})$ : $9.5 ; 13.1)$, the nonICM rate was 9.7 (95\% CI: $8.1 ; 11.4)$ and the ICM rate was 1.6 (95\% CI: 0.9; 2.3).

When we divide the follow-up period into the three calendar periods, the overall candidiasis rate decreased from

Table 3 Summary of the number and rates of children with candidiasis per 1,000 children with hospital admission/year in HIV-infected children and HIV-uninfected children by calendar periods

\begin{tabular}{|c|c|c|c|c|c|c|}
\hline \multirow[b]{2}{*}{ Description } & \multicolumn{2}{|r|}{ 1997-1999 } & \multicolumn{2}{|c|}{$2000-2002$} & \multicolumn{2}{|c|}{$2003-2008$} \\
\hline & No. & Rate $(95 \% \mathrm{Cl})$ & No. & Rate $(95 \% \mathrm{CI})$ & No. & Rate $(95 \% \mathrm{Cl})$ \\
\hline \multicolumn{7}{|l|}{ All candidiasis } \\
\hline HIV-uninfected children & 8 & $6.1(1.9 ; 10.3)$ & 4 & $3.1(0.1 ; 6.1)$ & 14 & $10.7(5.1 ; 16.3)$ \\
\hline HIV-infected children & 64 & $150.0(106.4 ; 175.5)$ & 41 & $90.3(62.7 ; 117.9)$ & 36 & $79.3(53.4 ; 105.2)$ \\
\hline p-value & & $<0.001$ & & $<0.001$ & & $<0.001$ \\
\hline \multicolumn{7}{|c|}{ Non-invasive Candida mycosis (Non-ICM) } \\
\hline HIV-uninfected children & 5 & $3.8(0.5 ; 7.1)$ & 3 & $2.3(0 ; 4.8)$ & 8 & $6.0(1.8 ; 10.2)$ \\
\hline HIV-infected children & 50 & $118.5(85.6 ; 151.3)$ & 36 & $85.3(57.4 ; 113.2)$ & 34 & $80.6(53.5 ; 107.6)$ \\
\hline p-value & & $<0.001$ & & $<0.001$ & & $<0.001$ \\
\hline \multicolumn{7}{|c|}{ Invasive Candida mycosis (ICM) } \\
\hline HIV-uninfected children & 3 & $1.2(0 ; 2.5)$ & 1 & $0.4(0 ; 1.1)$ & 6 & $2.3(0.5 ; 4.2)$ \\
\hline HIV-infected children & 14 & $32.4(15.4 ; 49.4)$ & 5 & $11.6(1.4 ; 21.7)$ & 2 & $4.6(0 ; 11.1)$ \\
\hline$p$-value & & $<0.001$ & & $<0.001$ & & 0.387 \\
\hline
\end{tabular}

Abbreviations: ICM, invasive candidiasis mycosis; HIV, Human immunodeficiency virus; Rate, events per 1,000 children with hospital admission/yea; $95 \%$ Cl, $95 \%$ of confidence interval.

Statistically significant differences are shown in bold. 
1997-1999 to 2000-2002 (18.8 to $11.5 ; \mathrm{p}<0.001)$ and from 2000-2002 to 2003-2008 (11.5 to 6.1; $\mathrm{p}=0.060$ ) (Figure 2). Within each category of candidiasis, both nonICM and ICM rates had significant decreases from 19971999 to $2003-2008$ (14.7 to $5.6(\mathrm{p}<0.001)$ and 4.1 to 0.3 $(\mathrm{p}<0.001)$, respectively) (Figure 2$)$. Finally, when we compared the two categories of candidiasis diagnoses, the non-ICM rates were higher than ICM rates throughout the whole follow-up and within each calendar period (Figure 2; $\mathrm{p}<0.001$ ).

\section{Discussion}

Other than for oral candidiasis, there is a scarcity of literature on the rate of candidiasis (invasive or non-invasive) among HIV-infected children. This report is a retrospective study on an important part of follow-up of HIVinfected children in Spain. In our study, HIV-infected children were at increased risk of developing candidiasis (ICM and non-ICM) compared to the general population, but these rates, as with all opportunistic infections, declined with the widespread use of HAART. In addition, ICM was more infrequent than non-ICM among children of the general population as well as among children with HIV infection.

Poor cell-mediated immunity in HIV-infected children often results in opportunistic infections, especially in advanced stages of HIV infection [11]. The candida species is the most common cause of fungal infection among HIV-infected children [16]. However, HAART-derived immune reconstitution is an important protective factor against candidiasis infection $[19,20]$. The recovery of cellular immunity with HAART may partially reverse susceptibility to opportunistic infections when it achieves sustained undetectable levels of HIV-RNA and CD4+ levels above 500 cells $/ \mathrm{mm}^{3}$ over a long period of time $[9,11]$. A high incidence of candidiasis diagnosis might be due to the lack of complete immune reconstitution and persistent CD4+ lymphopenia due to therapy failure [10]. The capacity of CD4+ recovery during long-term HAART in HIV-infected children with CD4+ levels below 5\% is lower than in children with CD4+ levels from 5-15\%, and restoration of the CD4+ cell percentage to a normal level is not necessarily achieved during long-term HAART [10]. Thus, continued surveillance of Candida infections may be important in order to assess the long-term effect of

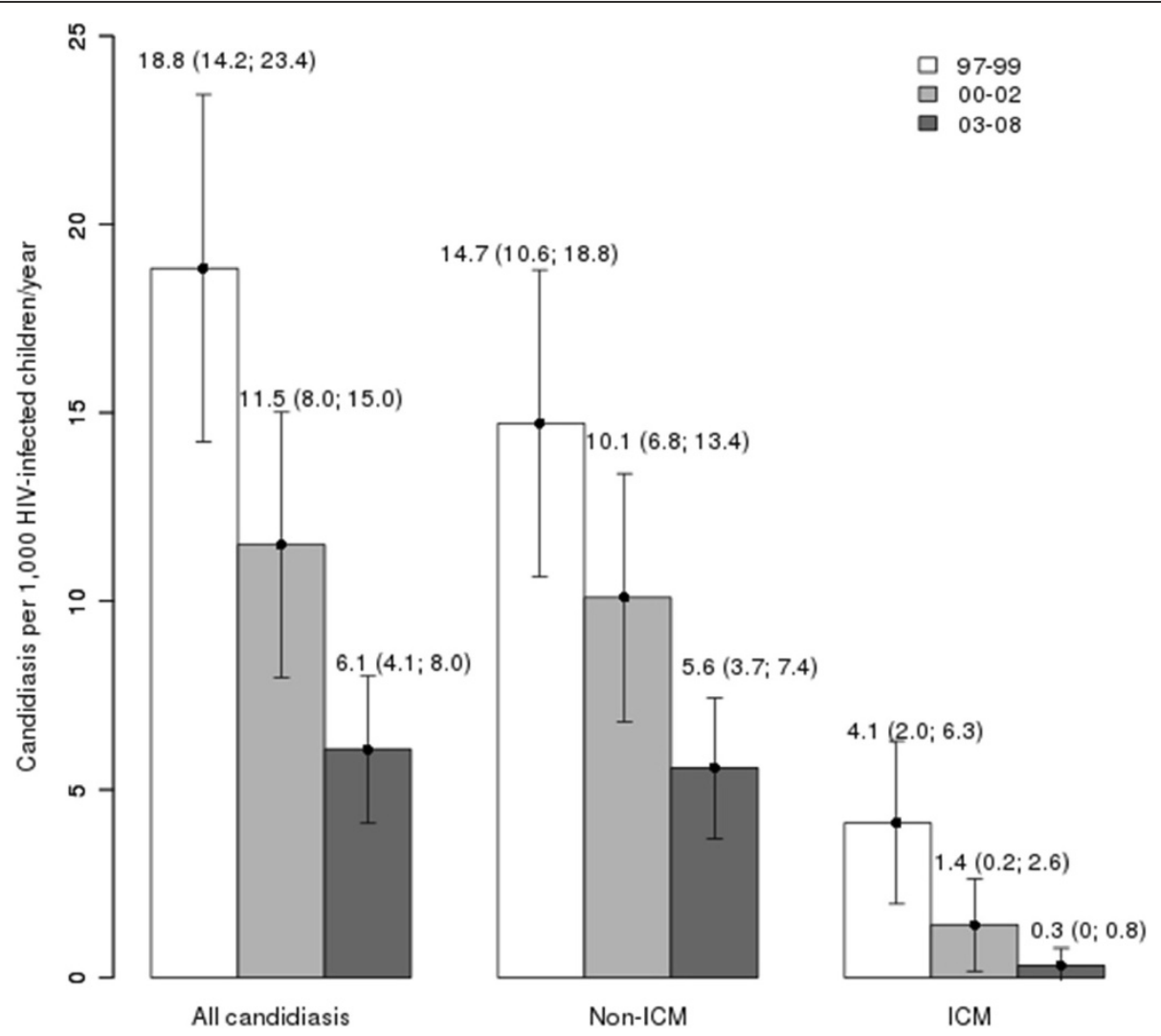

Figure 2 Summary of the epidemiologic trend of candidiasis (events per 1,000 HIV-infected children/year) among HIV-infected children in Spain by calendar periods. 
HAART on the occurrence of opportunistic infections in children.

Most candidiasis diagnoses were non-ICM and the rate of non-ICM diagnoses was higher in HIV-infected children than in HIV-uninfected children when children with hospital admissions were compared. However, these data should be interpreted with caution because they refer to primary and secondary diagnoses among children with hospital admissions. Since it is very rare for an HIV-uninfected child to be admitted to a hospital because of non-ICM such as oral candidiasis, the rate of non-ICM in HIV-uninfected children may be underestimated, as the database comes from hospital admissions only. Additionally, the rate of non-ICM children with hospital admissions decreased during follow-up, but no significant values were found. However, when we analyzed the data by children living with HIV/AIDS, the non-ICM rate decreased significantly in the last calendar period (20032008), reaching values similar to those of other pediatric populations infected with HIV $[11,18,22]$. This may be due to the extensive use of HAART and improved immunosurveillance, which is an important protective factor against candidiasis $[19,20]$. In addition, advances in HIV treatment, earlier diagnosis of infection status in exposed infants, and quantitative monitoring of virology and immunologic parameters may also have contributed to decreases in candidiasis rates. Moreover, the earlier HIV treatment starts over time, as per PENTA guidelines [23], the more non-ICM will be prevented.

Most ICM in children occur in the hospital setting, and this type of candidiasis is generally seen in severely immunocompromised persons such as cancer, transplant and AIDS patients, as well as nontrauma emergency surgery and critical ICU patients [24]. ICM is a leading cause of nosocomial mycosis with a high associated mortality [17]. In our study, HIV-infected children with ICM diagnoses had longer hospital stays than children with nonICM diagnoses, indicating that ICM diagnoses would appear in children with more serious clinical events and suppressed immune systems [24]. Moreover, our data show that HIV-infected children were at increased risk of developing ICM, although the ICM rate decreased during the follow-up. Thus, ICM rate in the last calendar period (2003-2008) was not higher in HIV-infected children than in the general population according to our study and other reports published $[17,25,26]$. Therefore, it is not as important of a health problem among HIV-infected children in the last years of the HAART era.

This study had several limitations that may impact our findings. This work was a retrospective study and we had no access to patient clinical data (antiretroviral treatment regimen, duration of HAART, CD4+ count, HIV viral load, CDC stage) that might have affected our results. MBDS data are anonymous and it is impossible to identify whether a patient has been hospitalized at different hospitals within the same calendar year. This may have caused a slight overestimation of our results because we may have calculated disease exacerbations or remissions as new participants. We cannot know the total number of HIVinfected children in Spain at present, because there is no national coverage data of HIV diagnoses of children in Spain. We used an estimation of the number of HIVinfected children in Spain, which was calculated from two reliable databases (Spanish National AIDS Register and Madrid Cohort HIV Children).

\section{Conclusions}

Although the candidiasis rate still remains higher than in the general population (from 1997 to 2008), candidiasis diagnoses decreased among HIV-infected children throughout the HAART era and it has ceased to be a major health problem among children with HIV infection in Spain.

\section{Additional file}

Additional file 1: Estimation of the number of children living with HIV/AIDS in Spain from 1997 to 2008.

\section{Abbreviations}

HIV: Human immunodeficiency virus; HAART: Highly active antiretroviral therapy; ICM: Invasive candida mycosis; non-ICM: Non-invasive candida mycosis; CD4+: CD4+ T-cell; MBDS: Minimum basic data set; ICD-9MC: International classification of diseases, 9th ed, clinical modification; AIDS: Acquired Immune Deficiency Syndrome.

\section{Competing interests}

The authors do not have any commercial or other association that might pose a conflict of interest.

\section{Authors' contributions}

Conception and design: AAM, SR. Analysis and interpretation of data: AAM, SR, DM, JJ. Drafting of the manuscript: SR, DM, JJ. Critical revision of the manuscript: AD, DG. Final approval of the version: SR. All authors read and approved the final manuscript.

\section{Acknowledgements}

Additional Contributions: We wish to thank: a) The Madrid HIV Paediatric Infection Collaborative Study Group (Santiago Jiménez de Ory, Dr. Jose Tomas Ramos, Dra. Ma Ángeles Muñoz-Fernandez) for records of HIV-infected children in Madrid cohort; b) The Spanish National AIDS Register (National Centre for Epidemiology, Instituto de Salud Carlos III, Madrid, Spain) for the number of HIV-infected children with an AIDS diagnocsis; c) Subdirección General del Instituto de Información Sanitaria (Ministerio de Sanidad, Servicios Sociales e Igualdad) for providing the information on which this study is based.

Financial support: This work has been supported by grants from Instituto de Salud Carlos III (Ref. PI08/0738 and PI11/00245 to SR and PI12/00019 to AAM).

\section{Author details}

'Unidad de Medicina Preventiva y Salud Pública, Universidad Rey Juan Carlos, Alcorcón, Madrid, Spain. ²Servicio de Pediatría, Hospital Infanta Cristina, Madrid, Parla, Spain. ${ }^{3}$ Servicio de Medicina Interna .Hospital General Universitario Gregorio Marañon, Madrid, Spain. ${ }^{4}$ Centro Nacional de Microbiología, Instituto de Salud Carlos III, Carretera Majadahonda- Pozuelo, Km 2.2, Madrid, Majadahonda 28220, Spain. ${ }^{5}$ Centro Nacional de 
Epidemiología, Instituto de Salud Carlos III, Madrid, Spain. ${ }^{6}$ Servicio de Pediatría, Hospital General Universitario Gregorio Marañon, Madrid, Spain.

Received: 10 October 2012 Accepted: 28 February 2013 Published: 4 March 2013

\section{References}

1. CDCP: Guidelines for use of antiretroviral agents in pediatric HIV infection. MMWR Morb Mortal Wkly Rep 1998, 47:1-43.

2. Mueller BU, Sleasman J, Nelson RP Jr, Smith S, Deutsch PJ, Ju W, Steinberg SM, Balis FM, Jarosinski PF, Brouwers P, et al: A phase I/II study of the protease inhibitor indinavir in children with HIV infection. Pediatrics 1998, 102(1):e8.

3. Rutstein RM, Feingold A, Meislich D, Word B, Rudy B: Protease inhibitor therapy in children with perinatally acquired HIV infection. AIDS 1997, 11:F107-111.

4. Krogstad P, Wiznia A, Luzuriaga K, Dankner W, Nielsen K, Gersten M, Kerr B, Hendricks A, Boczany B, Rosenberg M, et al: Treatment of human immunodeficiency virus 1 -infected infants and children with the protease inhibitor nelfinavir mesylate. Clin Infect Dis 1999, 28(5):1109-1118.

5. Starr SE, Fletcher CV, Spector SA, Yong FH, Fenton T, Brundage RC, Manion D, Ruiz N, Gersten M, Becker M, et al: Combination therapy with efavirenz, nelfinavir, and nucleoside reverse- transcriptase inhibitors in children infected with human immunodeficiency virus type 1. Pediatric AIDS Clinical Trials Group 382 Team. N Engl J Med 1999, 341(25):1874-1881.

6. Resino S, Bellón J, Resino R, Navarro M, Ramos J, Mellado M, de Jose M, Muñoz-Fernández MA: Extensive implementation of highly active antiretroviral therapy shows great effectiveness on the survival and surrogate markers in vertically HIV-infected children. Clin Infect Dis 2004, 38:1605-1612.

7. Viciana P, Rubio R, Ribera E, Knobel H, Iribarren JA, Arribas JR, Perez-Molina JA: [Longitudinal study on adherence, treatment satisfaction, and effectiveness of once-daily versus twice-daily antiretroviral therapy in a Spanish cohort of HIV-infected patients (CUVA study)]. Enferm Infecc Microbiol Clin 2008, 26(3):127-134.

8. Guillen S, Garcia San Miguel L, Resino S, Bellon JM, Gonzalez I, Jimenez de Ory S, Munoz-Fernandez MA, Navarro ML, Gurbindo MD, De Jose Ml, et al: Opportunistic infections and organ-specific diseases in HIV-1-infected children: a cohort study (1990-2006). HIV Med 2010, 11(4):245-252

9. Brady MT, Oleske JM, Williams PL, Elgie C, Mofenson LM, Dankner WM, Van Dyke RB: Declines in mortality rates and changes in causes of death in HIV-1-infected children during the HAART era. J Acquir Immune Defic Syndr 2010, 53(1):86-94.

10. Resino S, Resino R, Micheloud D, Gurbindo Gutierrez D, Leon JA, Ramos JT, Ciria L, de Jose I, Mellado J, Munoz-Fernandez A: Long-term effects of highly active antiretroviral therapy in pretreated, vertically HIV type 1infected children: 6 years of follow-up. Clin Infect Dis 2006, 42(6):862-869.

11. Gona P, Van Dyke RB, Williams PL, Dankner WM, Chernoff MC, Nachman SA, Seage GR 3rd: Incidence of opportunistic and other infections in HIVinfected children in the HAART era. JAMA 2006, 296(3):292-300.

12. Resino S, Resino R, Maria Bellon J, Micheloud D, Gutierrez MD, de Jose MI, Ramos JT, Fontelos PM, Ciria L, Munoz-Fernandez MA: Clinical outcomes improve with highly active antiretroviral therapy in vertically HIV type-1 -infected children. Clin Infect Dis 2006, 43(2):243-252.

13. Gibb DM, Duong T, Tookey PA, Sharland M, Tudor-Williams G, Novelli V, Butler K, Riordan A, Farrelly L, Masters J, et al: Decline in mortality, AIDS, and hospital admissions in perinatally HIV-1 infected children in the United Kingdom and Ireland. BMJ 2003, 327(7422):1019.

14. Kourtis AP, Bansil P, Posner SF, Johnson C, Jamieson DJ: Trends in hospitalizations of HIV-infected children and adolescents in the United States: analysis of data from the 1994-2003 Nationwide Inpatient Sample. Pediatrics 2007, 120(2):e236-243.

15. de Martino M, Tovo PA, Balducci M, Galli L, Gabiano C, Rezza G, Pezzotti P. Reduction in mortality with availability of antiretroviral therapy for children with perinatal HIV-1 infection. Italian register for HIV infection in children and the italian national AIDS registry. JAMA 2000, 284(2):190-197.

16. Mofenson LM, Brady MT, Danner SP, Dominguez KL, Hazra R, Handelsman E, Havens P, Nesheim S, Read JS, Serchuck L, et al: Guidelines for the prevention and treatment of opportunistic infections among HIV- exposed and HIV-infected children: recommendations from CDC, the national institutes of health, the HIV medicine association of the infectious diseases society of america, the pediatric infectious diseases society, and the american academy of pediatrics. MMWR Recommendations and reports: Morbidity and mortality weekly report Recommendations and reports / Centers for Disease Control 2009, 58(RR-11):1-166.

17. Pfaller MA, Diekema DJ: Epidemiology of invasive candidiasis: a persistent public health problem. Clin Microbiol Rev 2007, 20(1):133-163.

18. Nesheim SR, Kapogiannis BG, Soe MM, Sullivan KM, Abrams E, Farley J, Palumbo P, Koenig LJ, Bulterys M: Trends in opportunistic infections in the pre- and post-highly active antiretroviral therapy eras among HIVinfected children in the Perinatal AIDS Collaborative Transmission Study, 1986-2004. Pediatrics 2007, 120(1):100-109.

19. Weinberg A, Dickover R, Britto P, Hu C, Patterson-Bartlett J, Kraimer J, Gutzman H, Shearer WT, Rathore M, McKinney R: Continuous improvement in the immune system of HIV-infected children on prolonged antiretroviral therapy. AIDS 2008, 22(17):2267-2277.

20. Weinberg A, Pahwa S, Oyomopito R, Carey VJ, Zimmer B, Mofenson L, Kovacs A, Burchett SK: Antimicrobial-specific cell-mediated immune reconstitution in children with advanced human immunodeficiency virus infection receiving highly active antiretroviral therapy. Clin Infect Dis 2004, 39(1):107-114.

21. Alvaro-Meca A, Micheloud D, Jensen J, Diaz A, Garcia-Alvarez M, Resino S: Epidemiologic trends of cancer diagnoses among HIV-infected children in Spain from 1997 to 2008. Pediatr Infect Dis J 2011, 30(9):764-768.

22. Chiappini E, Galli L, Tovo PA, Gabiano C, Lisi C, Gattinara GC, Esposito S, Vigano A, Giaquinto C, Rosso R, et al: Changing patterns of clinical events in perinatally HIV-1-infected children during the era of HAART. AIDS 2007, 21(12):1607-1615.

23. Sharland M, Blanche S, Castelli G, Ramos J, Gibb DM: PENTA guidelines for the use of antiretroviral therapy, 2004. HIV Med 2004, 5(Suppl 2):61-86

24. Hacimustafaoglu M, Celebi S: Candida infections in non-neutropenic children after the neonatal period. Expert Rev Anti Infect Ther 2011, 9(10):923-940

25. Kao AS, Brandt ME, Pruitt WR, Conn LA, Perkins BA, Stephens DS, Baughman WS, Reingold AL, Rothrock GA, Pfaller MA, et al: The epidemiology of candidemia in two United States cities: results of a population-based active surveillance. Clin Infect Dis 1999, 29(5):1164-1170.

26. Neu N, Malik M, Lunding A, Whittier S, Alba L, Kubin C, Saiman L: Epidemiology of candidemia at a Children's hospital, 2002 to 2006. Pediatr Infect Dis J 2009, 28(9):806-809.

doi:10.1186/1471-2334-13-115

Cite this article as: Álvaro-Meca et al:: Rate of candidiasis among HIVinfected children in Spain in the era of highly active antiretroviral therapy (1997-2008). BMC Infectious Diseases 2013 13:115.

\section{Submit your next manuscript to BioMed Central and take full advantage of:}

- Convenient online submission

- Thorough peer review

- No space constraints or color figure charges

- Immediate publication on acceptance

- Inclusion in PubMed, CAS, Scopus and Google Scholar

- Research which is freely available for redistribution 